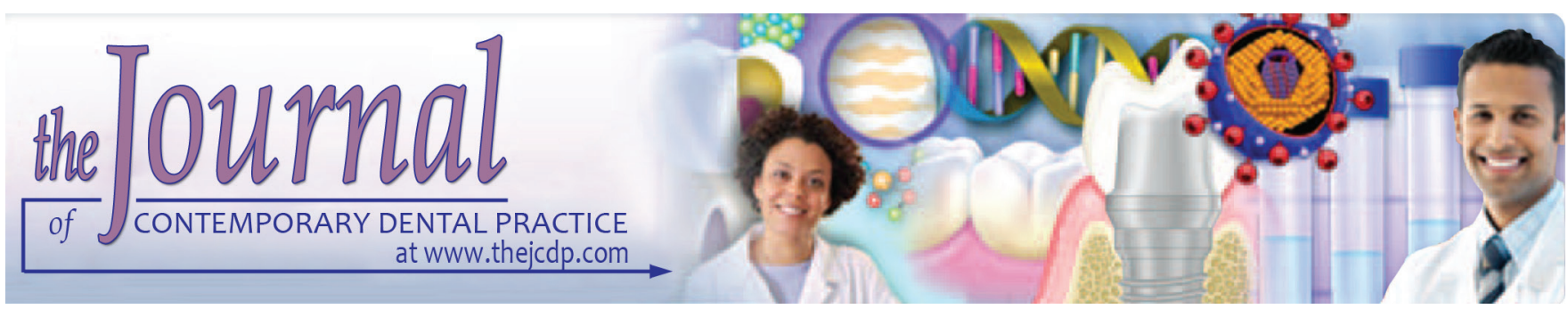

\title{
An in situ Evaluation of Bioactives on the Morphology of Bleached Enamel
}

\author{
${ }^{1}$ Thiago da Rosa Nogueira, ${ }^{2}$ Larissa Dias Alexandrino, ${ }^{3}$ Yasmin do Socorro Batista de Lima Gomes \\ ${ }^{4}$ Cristiane de Melo Alencar, ${ }^{5}$ Eliane Bemerguy Alves, ${ }^{6}$ Cecy Martins Silva
}

\section{ABSTRACT}

Aim: The aim of this study was to use surface rugosity analysis (Ra) and scanning electron microscopy (SEM) comparing effects of nano-hydroxyapatite (NANO), casein phosphopeptideamorphous calcium phosphate (CPP-ACP), and NovaMin (NOVA) on enamel's human morphology bleached with $37.5 \%$ hydrogen peroxide.

Materials and methods: Forty specimens $(3 \times 3 \times 3 \mathrm{~mm})$ were obtained from fully included third molars and four specimens were attached in the first molars of the volunteers. The POLApositive control has only been bleached. Three experimental groups were bleached and treated with respective bioactive: NANO, CPP-ACP, and NovaMin. The Ra analyses were performed before and after the treatment using a rugosimeter. The obtained photomicrographs were analyzed using SEM $(n=3)$ by three examiners, and the study was double blind.

Results: The Ra results were analyzed by one-way analysis of variance and Tukey's post hoc test $(p<0.05)$. All experimental groups showed significant differences of the others; however, the experimental groups were not significantly different from each other.

Conclusion: The enamel morphology of the bioactive-treated groups had more regular surfaces, than the others.

Keywords: Bioactive agents, NANO-P, Rugosity analysis, Scanning electron microscopy.

How to cite this article: da Rosa Nogueira T, Alexandrino LD, de Lima Gomes YSB, de Melo Alencar C, Alves EB, Silva CM. An in situ Evaluation of Bioactives on the Morphology of Bleached Enamel. J Contemp Dent Pract 2016;17(3):192-197.

Source of support: Nil

Conflict of interest: None

\footnotetext{
${ }^{1-6}$ Department of Restorative Dentistry, Federal University of Pará, Para, Brazil
}

Corresponding Author: Cecy Martins Silva, Professor Augusto Correa Street no. 1, Guamá, Belém, Pa, CEP: 66075110, Brazil, Phone: +559132521269, e-mail: cecymsilva@ gmail.com

\section{INTRODUCTION}

The growing demand for bleaching treatments is directly related to their efficiency and ease of implementation by the professional. Researchers have long been interested in developing techniques and products that are more secure and that have fewer impacts on tooth structure. ${ }^{1}$ Several studies have reported that bleaching treatment is associated with unwanted effects on the enamel and dentin, such as a decrease in wear resistance, changes in the surface rugosity of the enamel, ${ }^{2}$ decreased hardness, and instances of hypersensitivity that result from demineralization of the tooth structure related to the bleaching agents. ${ }^{3-5}$

To minimize these deleterious effects, remineralizing products, such as bioactive agents, have been added to hydrogen peroxide bleaching treatments; these efforts have achieved satisfactory results. ${ }^{6,7}$ Casein phosphopeptide-amorphous calcium phosphate (CPP-ACP) and nano-hydroxyapatite and sodium and calcium phosphosilicate (NovaMin) have been reported to be effective $\mathrm{e}^{7-10}$; however, there is a need for greater clarification regarding the clinical use of these products.

The basis for the effective remineralization of dental enamel is the presence of a source of $\mathrm{P}$ and $\mathrm{Ca}$ ions, as these ions are quite soluble, so they are difficult to apply and concentrate on the enamel surface. With regard to this difficulty, casein phosphopeptide has the ability to stabilize calcium phosphate, which ensures the interaction necessary for the incorporation of these ions into the dental structure. ${ }^{11,12}$

NovaMin is an inorganic compound (bioglass) that consists of sodium, phosphate, calcium, and silica; the compound produces a quick release of calcium, sodium, and phosphorus ions that aid in the formation of the hydroxyapatite layer. ${ }^{13,14}$ When deposited on the tooth surface in vivo, bioactive glass forms a layer of amorphous 
film that is rich in $\mathrm{Ca}^{2+}$ and $\mathrm{PO}_{4}{ }^{3-}$, which crystallizes through the incorporation of $\mathrm{OH}^{-}$and $\mathrm{CO}_{3}{ }^{2-}$ anions that are present in the solution and forms a layer of hydroxyapatite. ${ }^{15}$

The aim of this study was to use surface rugosity analysis ( $\mathrm{Ra}$ ) and scanning electron microscopy (SEM) to evaluate in situ the effects of bioactive agents on human enamel that had been bleached with 38\% hydrogen peroxide. The null hypothesis of this study was that the bioactive agents would not influence the morphology of the enamel that was bleached with high-concentration hydrogen peroxide.

\section{MATERIALS AND METHODS}

This work was examined and approved under protocol number 335,938 by the ethics committee of the Institute of Health Sciences Federal University of Para, Brazil.

\section{Sample Preparation}

For this study, fully included third molars that showed no morphological or structural damage or defects, such as cracks, fractures, or caries, were selected. The molars were cleaned and stored in distilled water until preparation. Crown/root separation was performed to the limit of the cement enamel junction with the aid of a no. 4138 diamond drill (KG Sorensen, Cotia, São Paulo, Brazil) under air/ water coolant. To obtain $40(3 \times 3 \times 3 \mathrm{~mm})$ specimens, the buccal crown surfaces were cut with a double-sided steel disc (KG Sorensen) activated by a micromotor at low speed (KAVO, Berlin, Steglitz, Germany) and regularized with no. 4138 diamond burs (KG Sorensen, Cotia, São Paulo, Brazil). The pieces were divided into groups according to the bioactive agent used (Table 1).

To obtain enamel prisms with the same inclinations, the pieces always corresponded to the central area of the buccal crown surface. The surfaces of the specimens were flattened with water sandpaper (Saint-Gobain Abrasives Ltd., São Paulo, Brazil) with successive granulations of 400, 600, and 1200 and a felt disk (TDV Dental Ltda., Santa Catarina, Brazil), which was coated with an aluminum polishing paste (Alpha Micropolishâ 10 - Union Carbide,

Table 1: Summary of experimental conditions

\begin{tabular}{ll}
\hline Experimental test & Groups \\
\hline Surface rugosity $(n=12)$ & POLA (control) \\
& CPP-ACP \\
& NANO \\
& NOVA \\
SEM $(n=3)$ & POLA (control) \\
& CPP-ACP \\
& NANO \\
& NOVA \\
\hline
\end{tabular}

Greensburg, LA, USA). The tooth pieces were stored in distilled water until use.

\section{Clinical Phase}

The volunteers were students from the College of Dentistry at Federal University of Para, and were aged between 20 and 22 years and answered a health questionnaire and were clinically examined and selected according to the following inclusion criteria: clinical crown height of the molars greater than $5 \mathrm{~mm}$; absence of caries, periodontal disease, dentin sensitivity or gastroesophageal disturbances; a normal oral $\mathrm{pH}$; and normal salivary flow. The following exclusion criteria were also applied: pregnancy, lactating, wearing fixed dentures or removable orthodontic appliances, drug uses, smoking, and practicing water sports. The volunteers were informed about the study procedures and signed an informed consent form.

Each volunteer received four dental pieces (Fig. 1). Using the Adper Single Bond 2 adhesive system (3M/ ESPE, São Paulo, Brazil) and the cementing agent RelyX ARC (3M/ESPE, São Paulo, Brazil), the pieces were photopolymerized with LED photopolymer (Radii, SDI Limited, Bayswater, Victoria, Australia) onto the buccal surfaces of the first upper and lower molars according to the methodology described in 2007 by Faraoni-Romano et al. ${ }^{16}$ All materials were handled according to the manufacturer's guidelines.

After the bleaching treatments, the bleached surfaces were polished with a felt disk that was coupled to a chuck at low speed using a universal polishing paste (FGM, Santa Catarina, Brazil).

For oral hygiene during the development period of the bleaching treatment, the volunteers were given Colgate Total 12 fluoride toothpaste (Colgate-Palmolive, São Paulo, SP, Brazil). After the bleaching, the pieces were removed for laboratory analysis.

\section{Treatment with Bleaching Agent}

After the application and polymerization of the gingival barrier (SDI), a 37.5\% Pola Office bleaching agent (SDI

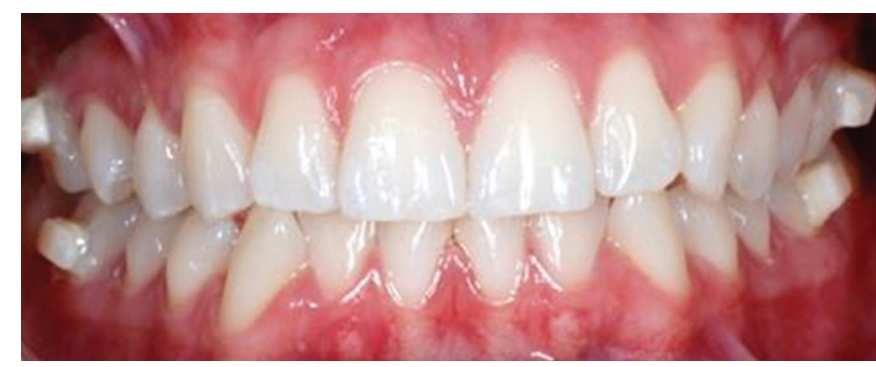

Fig. 1: Specimens fixed on the buccal surface of the first upper and lower molars 
Limited, Bayswater, Victoria, Australia) was applied to the buccal surfaces of the patient's teeth and to the specimens for 30 minutes. The sessions were held weekly for 3 weeks.

\section{Treatment with Bioactive Agents}

After treatment with the bleaching agent, remineralizing agents were applied for 5 minutes per group to the specimens and buccal surfaces of the patients' teeth using a disposable applicator (Microbrush/Vigodent); the agents were removed with air/water jets. The bioactive agents and their chemical composition are summarized in Table 2.

\section{Analysis of Surface Rugosity}

Three measurements were performed using a rugosimeter (Surftest SJ-301; Mitutoyo, Kanagawa, Japan) to obtain the mean rugosity $(\mathrm{Ra})$. The specimens were supported in utility wax (NewWax, Technew, Rio de Janeiro, Brazil) to aid in fixing the piece to the apparatus and to avoid reading errors. Specimens with an initial rugosity in the range of 0.15 to $0.21 \mathrm{Ra}$ were selected for further analysis.

The initial Ra analysis (baseline) was performed prior to fixing the specimens on the volunteers' teeth. The final Ra analysis was performed after the specimens were removed, which was 24 hours after the last treatment session.

\section{Scanning Electron Microscopy}

After the analysis of surface roughness, three specimens from each group were examined under a scanning electron microscope (LEO Model 1450 VP; LEO Electron Microscopy Ltd., Clifton Road, UK) at 4000× and 6000× magnification using $10 \mathrm{kV}$. The entire buccal surface was digitalized, and the most critical areas were selected for electron microscopy photomicrograph digitalization.

All specimens were initially dried for 7 days and subsequently metallized with gold ( $\mathrm{Au}$ ) using a Emitech K550 sputter, which resulted in the deposition of a film

Table 2: Manufacturer and active chemical composition of the products that were used in the study

\begin{tabular}{|c|c|c|}
\hline Product & Manufacturer & Active chemical composition \\
\hline $\begin{array}{l}\text { Pola Office } \\
37.5 \%\end{array}$ & $\begin{array}{l}\text { Southern Dental } \\
\text { Industries (SDI) }\end{array}$ & $37.5 \%$ hydrogen peroxide \\
\hline Nano-P & $\begin{array}{l}\text { FGM } \\
\text { Odontological } \\
\text { Products LTDA }\end{array}$ & $\begin{array}{l}\text { Nanometric calcium phosphate } \\
\text { (in the form of hydroxyapatite), } \\
9000 \text { ppm sodium fluoride, } 5 \% \\
\text { potassium nitrate }\end{array}$ \\
\hline $\begin{array}{l}\text { MI Paste } \\
\text { Plus }\end{array}$ & Recaldent & $\begin{array}{l}0.2 \% \text { sodium fluoride, } 10 \% \\
\text { CPP-ACP }\end{array}$ \\
\hline $\begin{array}{l}\text { Sensodyne } \\
\text { Repair and } \\
\text { Protect }\end{array}$ & Sensodyne & $\begin{array}{l}\text { Sodium monofluorophosphate } \\
\text { (1450 ppm), 5\% NovaMin }\end{array}$ \\
\hline
\end{tabular}

with a mean thickness of $\pm 15 \mathrm{~nm}$ (nanometers) on the specimens

\section{Statistical Analysis}

A one-way analysis of variance (ANOVA) test was used to analyze the significance between the initial and final Ra means between the groups. The BioEstat 5.0 statistical software was used for all analyses, and statistical significance was set at 5\%.

As a complementary exercise, the percentage decrease of surface rugosity (\%DRa) was calculated for each group according to the following formula:

$$
\% \mathrm{DRa}=\left(\frac{\text { initial } \mathrm{Ra}-\text { final } \mathrm{Ra}}{\text { initial } \mathrm{Ra}}\right) \times 100
$$

\section{RESULTS}

\section{Surface Rugosity}

Table 3 summarizes the results of the surface rugosity analysis. The comparison between the initial and final rugosity of each experimental group showed a significant difference. There was no significant difference in the initial readings of the different groups $(p>0.05)$. The final readings of the experimental groups showed a significant difference compared with its initial readings. However, the NANO, CPP-ACP, and NOVA groups did not significantly differ from each other $(p<0.01)$. The POLA group had the highest mean Ra and was significantly different than the other groups. The NANO, CPP-ACP, and NOVA groups had the highest \%DRa compared with its initial readings, and the POLA group had the lowest \%DRa (Table 4).

Table 3: Comparison of mean and standard deviation of surface rugosity ( $\mathrm{Ra}$ ) of the groups, evaluated by Tukey test tens specimens in each group

\begin{tabular}{llll}
\hline & \multicolumn{2}{l}{ Initial Ra } & Final Ra \\
\cline { 2 - 3 } Groups* & $\begin{array}{l}\text { Mean and standard } \\
\text { deviation }\end{array}$ & $\begin{array}{l}\text { Mean and standard } \\
\text { deviation }\end{array}$ \\
\hline POLA (control) & $0.17 \pm 0.01 \mathrm{Ba}$ & $0.21 \pm 0.01 \mathrm{Ac}$ \\
CPP-ACP & $0.18 \pm 0.01 \mathrm{Ba}$ & $0.09 \pm 0.01 \mathrm{Aa}$ \\
NOVA & $0.17 \pm 0.01 \mathrm{Ba}$ & $0.08 \pm 0.01 \mathrm{Aa}$ \\
NANO & $0.17 \pm 0.01 \mathrm{Ba}$ & $0.08 \pm 0.01 \mathrm{Aa}$ \\
\hline
\end{tabular}

${ }^{*}$ Groups with the same letter are statistically similar, capital letters on the vertical and lowercase letters on the horizontal

Table 4: Percentage decrease in surface rugosity (\%DRa) in the experimental groups

\begin{tabular}{ll}
\hline Groups & $\%$ DRa \\
\hline POLA (control) & $-22.73 \%$ \\
CPP-ACP & $49.81 \%$ \\
NOVA & $51.71 \%$ \\
NANO & $50.68 \%$ \\
\hline
\end{tabular}




\section{Scanning Electron Microscopy}

The photomicrographs of the POLA group (Fig. 2) showed more substantial morphological changes than the other groups. The changes were characterized by the presence of depressions, erosion, porosity, and surface irregularities. The surface morphologies of the groups that were treated with bioactive agents (Figs 3 to 5) showed similar morphological characteristics to each other: a regular, mineralized enamel surface was observed without erosions, marked depressions, or prismatic exposure compared with the positive control group.

\section{DISCUSSION}

Tooth bleaching is a widespread but controversial procedure. In the literature, conflicting results regarding the ability of bleaching agents to cause morphological enamel changes are reported. ${ }^{17,18}$ These conflicting results are caused by a lack of standardization of methodologies. Specifically, there is variation across studies in the duration of the bleaching process and the concentration of the bleaching agents. ${ }^{7}$

In the present study, the POLA group had the highest mean Ra compared with the other groups, which suggests that the POLA group had the highest degree of demineralization. This possibility was confirmed by the $\% \mathrm{DRa}$, as the POLA group presented the lowest reduction of rugosity, suggesting that a high concentration of hydrogen peroxide impairs enamel morphology. Previous studies have shown that enamel submitted to bleaching treatment causes an increase in Ra because of

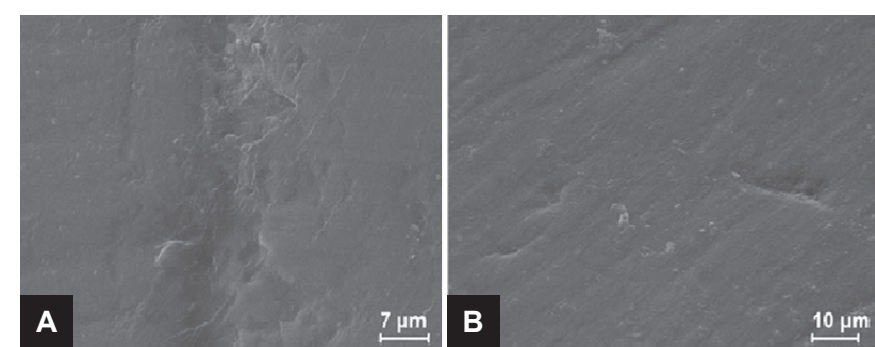

Fig. 2: The POLA group under 4000x (A) and 6000x

(B) magnification
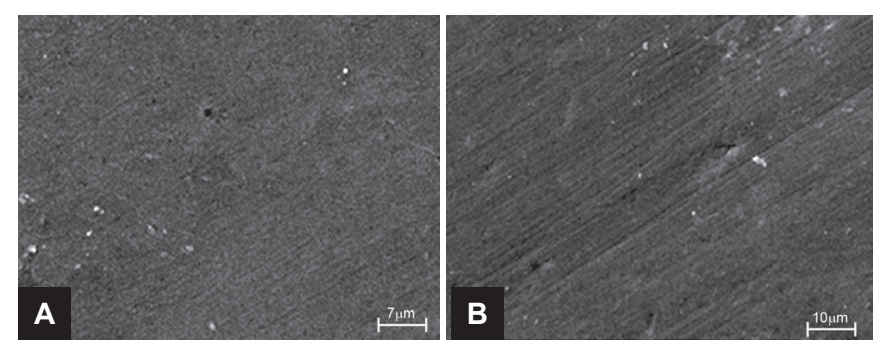

Fig. 4: The CPP-ACP group under 4000x (A) and $6000 \times(B)$ magnification the action of hydrogen peroxide, which penetrates the tooth structure, denatures proteins and oxidizes organic compounds, ${ }^{19}$ and confers the increased permeability of enamel and dentin. ${ }^{20,21}$ The morphological analysis of the photomicrographs in this group showed an increase in porosity and surface irregularities of the enamel, which confirms the results that were obtained for Ra.

The statistical analysis showed that the groups that were treated with bioactive agents had reduced mean Ra values and increased \%DRa compared with the initial readings of each group and with the positive control group (POLA). This finding shows that the agent is effective at preserving the enamel structure. The photomicrographs showed a more regular surface without porosity, pronounced irregularities, or enamel prism exposure, which confirms the Ra results.

The deposition of nanocrystals, which is promoted by nano-hydroxyapatite, forms a layer of replacement calcium and phosphate ions on the demineralized surfaces; the layer has biomimetic properties and exhibits chemical-physical characteristics that have an affinity for demineralized enamel regions. ${ }^{22,23}$ This layer may have contributed to the decrease in morphological changes to the bleached enamel.

The interaction of fluoride with the CPP-ACP complex as a source of $\mathrm{Ca}$ and $\mathrm{P}$ is critical. In addition to the remineralization process that occurs as a result of the deposition of stabilized calcium phosphate on the enamel surface, this interaction confers the anticariogenic property of $\mathrm{F}$ ions. The isolated application of fluoride to the teeth does not produce the necessary conditions for the formation
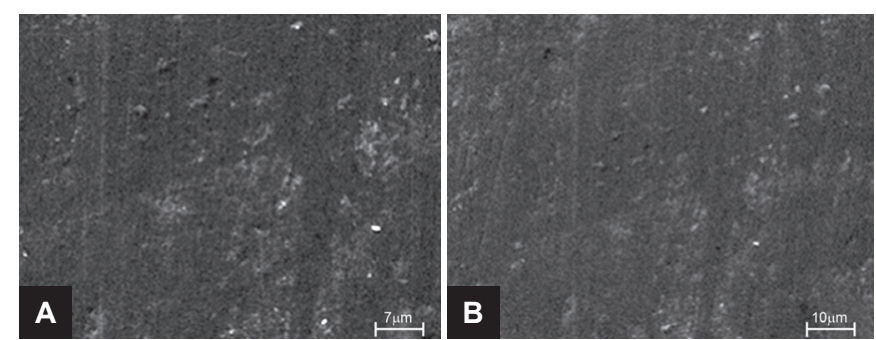

Fig. 3: The NANO group under $4000 \times(A)$ and $6000 \times$ (B) magnification
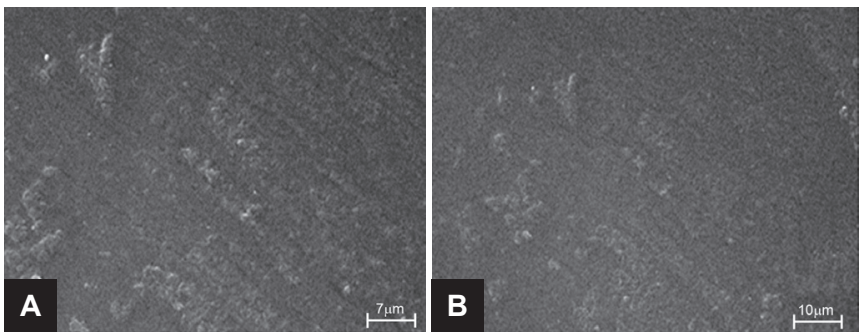

Fig. 5: The NOVA group under $4000 \times(A)$ and $6000 \times$ (B) magnification 
of fluorapatite, as there is a lack of stable $\mathrm{Ca}$ and $\mathrm{P}$ in the oral environment. ${ }^{24,25}$ The use of a paste that contains CPP-ACP and 0.2\% (900 ppm) fluoride may favor remineralization and the formation of a new layer of fluorapatite on the enamel surface. Together with post-treatment polishing, these conditions result in the filling of morphological irregularities and smoothing of the enamel surface.

In an in vitro study, Cunha et $\mathrm{al}^{26}$ showed that the application of a CCP-ACP paste before and after bleaching at home and during surgery prevented the negative changes in rugosity and tooth structure and did not harm the bleaching treatment.

Following contact between NovaMin and the enamel surface and saliva, the formation of a layer of calcium phosphate supplies $\mathrm{P}$ and $\mathrm{Ca}$ for the crystallization of hydroxyapatite. ${ }^{27}$ The NovaMin is an inorganic substance comprising sodium phosphate, silica, and calcium. ${ }^{28}$ The high levels of calcium ions and phosphate released from this folder into contact with dentin and its deep penetration into the dentinal tubules may suggest that these calcium and phosphate ions are able to penetrate the surface and remineralize the demineralized enamel. Remineralizing agents containing calcium and phosphate have reported high penetration and better remineralization throughout the depth of enamel. ${ }^{29}$

In this work, the hydroxyapatite neo formation was satisfactory, as the mean Ra values were reduced and the enamel surface was made more regular and homogeneous without conferring significant depressions.

Previous studies have demonstrated ${ }^{7}$ that when applied to the surface of bleached human enamel, NovaMin may cause remineralization in the damaged enamel surfaces, as NovaMin is difficult to remove via tooth brushing. In the present study, the storage of specimens in the oral environment allowed us to obtain results that approximated clinical conditions by favoring the natural ionic exchanges between enamel and saliva that can positively influence the remineralization of the tooth structure. ${ }^{30}$ Most published works have been developed in laboratory conditions that do not reflect the conditions found in the oral environment. The oral cavity presents several factors that can affect the action of the bleaching agent, such as the presence of saliva, which has a buffering capacity related to the bicarbonate and phosphate system. In addition to enzymes and bacteria, saliva contains inorganic electrolytes, such as phosphorus, calcium, and fluoride. These features of the oral environment complicate comparisons of results that are obtained from in situ studies. ${ }^{30,31}$

During the present research, the toothpaste that was used by volunteers for cleaning included fluoride, which may have interacted with the bioactive agents along with the saliva, thereby enhancing the action mechanism of the bioactive agents.

The application time of the Nano-P, CPP-ACP, and NovaMin agents (5 minutes) was sufficient to obtain satisfactory results on the enamel surface. This finding suggests a favorable indication for the use of these agents in surgery. For treatment purposes, these agents can be combined with bleaching treatments without influencing the professional's time.

The null hypothesis of this study was rejected, as the bioactive agents positively influenced the morphology of the enamel that was bleached with high-concentration hydrogen peroxide, due to the high bioactivity of the used agents, which increases the superficial area and the capacity of rinsing the enamel, favoring the formation of a calcium and phosphate layer. The solubility of these materials allows the releasing of calcium and phosphate ions on the oral environment, on the appropriate concentrations and velocity, contributing for a remineralization of the enamel.

\section{CONCLUSION}

The use of pastes containing nano-hydroxyapatite, CPPACP, and NovaMin reduced the detrimental effects of high-concentration hydrogen peroxide on the surface morphology of human enamel.

\section{CLINICAL SIGNIFICANCE}

Evaluate in situ the effects of bioactive agents on human enamel that had been bleached with 38\% hydrogen peroxide and thus enable an effective treatment to decrease the deleterious effects of bleaching and encourage future research on this topic.

\section{REFERENCES}

1. Dietschi D, Rossier S, Krejci I. In vitro colorimetric evaluation of the efficacy of various bleaching methods and products. Quintessence Int 2006 Jul-Aug;37(7):515-526.

2. Sahar A. Environmental scanning electronic microscope study of enamel surface after using three different bleaching agents. J Am Sci 2011;7:1-6.

3. Pinto CF, Oliveira RD, Cavalli V, Giannini M. Peroxide bleaching agent effects on enamel surface microhardness, roughness and morphology. Braz Oral Res 2004 Oct-Dec;18(4): 306-311.

4. Arruda AM, Dos Santos PH, Sundfeld RH, Berger SB, Briso AL. Effect of hydrogen peroxide at $35 \%$ on the morphology of enamel and interference in the de-remineralization process: an in situ study. Oper Dent 2012 Sep-Oct;37(5):518-525.

5. Basting RT, Amaral FL, França FM, Flório FM. Clinical comparative study of the effectiveness of and tooth sensitivity to $10 \%$ and $20 \%$ carbamide peroxide home-use and $35 \%$ and $38 \%$ hydrogen peroxide in-office bleaching 
materials containing desensitizing agents. Oper Dent 2012 Sep-Oct;37(5):464-473.

6. Pinheiro BH, Lopes B, Klautau BE, Cardoso J, Silva BR, Cardoso PEC. Influence of bioactive materials used on the dentin surface whitened with carbamide peroxide $16 \%$. Mater Res 2010 Apr-Jun;13(2):273-278.

7. Gjorgievska E, Nicholson JW. Prevention of enamel demineralization after tooth bleaching by bioactive glass incorporated into toothpaste. Aust Dent J 2011 Jun;56(2):193-200.

8. Grobler SR, Majeed A, Moola MH, Roelof RJ, Theuns Van WK. In vivo spectrophotometric assessment of the tooth whitening effectiveness of Nite White $10 \%$ with amorphous calcium phosphate, potassium nitrate and fluoride, over a 6-month period. Open Dent J 2011 Apr;5:18-23.

9. Pedreira de FAC, Botta SB, Teixeira FDS, Salvadori MC, Garone NN. Effects of fluoride or nanohydroxiapatite on roughness and gloss of bleached teeth. Microsc Res Tech 2011 Dec;74(12):1069-1075.

10. De Vasconcelos AA, Cunha AG, Borges BC, Machado CT, Dos Santos AJ. Tooth whitening with hydrogen/carbamide peroxides in association with a CPP-ACP paste at different proportions. Aust Dent J 2012 Jun;57(2):213-219.

11. Pardal D, Hegde M, Shetty S. Remineralization of enamel sub-surface lesion using casein phosphopeptide amorphous calcium phosphate (CPP-ACP): a quantitative energy dispersive X-ray analysis (EDAX). J Conserv Dent 2007;10:19-25.

12. Morgan MV, Adams GG, Bailey DL, Tsao CL, Fischman SL, Reynolds EC. The anticariogenic effect of sugar-free gum containing CPP-ACP nanocomplexes on approximal caries determined using digital bitewing radiography. Caries Res 2008;42(3):171-184.

13. Rajesh KS, Hedge S, Arun KMS, Shetty DG . Evaluation of the efficacy of a $5 \%$ calcium sodium phosphosilicate (Novamin) containing dentifrice for the relief of dentinal hypersensitivity: a clinical study. Indian J Dent Res 2012 May-Jun;23(3):363-367.

14. Gendreau L, Barlow APS, Mason SC. Overview of the clinical evidence for the use of NovaMin in providing relief from the pain of dentin hypersensitivity. J Clin Dent 2011;22(3):90-95.

15. Siqueira RL, Zanotto ED. Biosilicate: historical of a highly active Brazilian glass-ceramic. Quim Nova 2011;34:1231-1241.

16. Faraoni RJJ, Turssi CP, Serra MC. Effect of a $10 \%$ carbamide peroxide on wear resistance of enamel and dentine: in situ study. J Dent 2009 Apr;37(4):273-278.

17. Li Y. Safety controversies in tooth bleaching. Dent Clin North Am 2011 Apr;55(2):255-263.

18. Esberard RR, Consolaro A, Esberard RM, Bonetti I, Esberard RR. Effects of technical and external bleaching agents on the morphology of the cementoenamel junction and dental tissues that compose it. R Dental Press Estet 2004;1:58-72.
19. Paulo R, Araújo C D E. Carbamide peroxide on human enamel. Ciênc Rev Med Biol 2007; 6:100-121.

20. Souza RO, Lombardo GH, Pereira SM, Zamboni SC, Valera MC, Araujo MA, Ozcan M. Analysis of tooth enamel after excessive bleaching: a study using scanning electron microscopy and energy dispersive $x$-ray spectroscopy. Int J Prosthodont 2010 Jan-Feb;23(1):29-32.

21. Paula SDS, Soares LE, Do Espírito Santo AM, Martin AA, Cavalli V, Liporoni PC. FT-Raman and energy dispersive x-ray fluorescence spectrometric analyses of enamelsubmitted to $38 \%$ hydrogen peroxide bleaching, an acidic beverage, and simulated brushing. Photomed Laser Surg 2010 Jun;28(3):391-396.

22. Li L, Pan H, Tao J, Xu X, Mao C, Gu X, Tang R. Repair of enamel by using hydroxyapatite nanoparticles as the building blocks. J Mater Chem 2008;18:4079-4084.

23. Swarup J S, Rao A. Enamel surface remineralization: using synthetic nanohydroxyapatite. Contemp Clin Dent 2012 Oct;3(4):433-436.

24. Rao A, Malhotra N. The role of remineralizing agents in dentistry: a review. Compend Contin Educ Dent 2011 Jul-Aug;32(6):26-33.

25. Moezizadeh M, Moayedi S. Anticariogenic effect of amorphous calcium phosphate stabilized by casein phosphopeptid: a review article. Res J Biol Sci 2009;4:132-136.

26. Cunha AG, De Vasconcelos AA, Borges BC, Vitoriano Jde O, Alves-Junior C, Machado CT, Dos Santos AJ. Efficacy of in-office bleaching techniques combined with the application of a casein phosphopeptide-amorphous calcium phosphate paste at different moments and its influence on enamel surface properties. Microsc Res Tech 2012 Aug;75(8):1019-1025.

27. Walker GD, Cai F, Shen P, Adams GG, Reynolds C, Reynolds EC. Casein phosphopeptide-amorphous calcium phosphate incorporated into sugar confections inhibits the progression of enamel subsurface lesions in situ. Caries Res 2010;44(1): 33-40.

28. Rajesh K, Hedge S, Arun Kumar MS, Shetty DG. Evaluation of the efficacy of a $5 \%$ calcium sodium phosphosilicate (Novamin) containing dentifrice for the relief of dentinal hypersensitivity: a clinical study. Indian J Dent Res 2012 May-Jun;23(3):363-367.

29. Bakry AS, Marghalan HY, Omayma OA, Taqami J. The effect a bioglass paste on enamel exposed to erosive challenge. J Dent 2014 Nov;42(11):1458-1463.

30. Faraoni-Romano JJ, Turssi CP, Serra MC. Effect of a $10 \%$ carbamide peroxide on wear resistance of enamel and dentine: in situ study. J Dent 2009 Apr;37(4):273-278.

31. Smidt A, Feuerstein O, Topel M. Mechanical, morphologic, and chemical effects of carbamide peroxide bleaching agents on human enamel in situ. Quintessence Int 2011 May;42(5):407-412. 